\title{
Influencia de la degradación del Clorpirifos en la detección analítica utilizando biosensores: revisión del estado actual y aspectos futuros ${ }^{1}$
}

\author{
Influence of Chlorpyriphos degradation on analytical detection \\ using biosensors: current status review and future aspects
}

\author{
M. Torres, K. Pozo y V. Díaz \\ Recibido: enero 22 de 2021 - Aceptado: septiembre 22 de 2021
}

\begin{abstract}
Resumen- El Clorpirifós (CP) es un pesticida ampliamente utilizado, relacionado a diversos daños en salud y dado a su ubicuidad, su monitoreo ha adquirido relevancia para evaluar el estado y tasas de descarga al medioambiente. Por su parte, los factores ambientales favorecen la degradación de CP y disipación en el medio ambiente, dificultando su trazabilidad y detección real en las diversas matrices. En la actualidad, el uso de biosensores proporciona técnicas analíticas prometedoras para la detección de diversos compuestos de importancia ambiental, pero se desconoce si la degradación natural de dichos compuestos afectaría el correcto reconocimiento por parte de los biosensores, influyendo en su uso como herramienta de trazabilidad. El objetivo principal de esta revisión es abordar los recientes avances de biosensores para la detección de CP, sus desafíos en la detección en muestras reales asociados a la degradación de este contaminante y los aspectos futuros asociados al monitoreo ambiental de este pesticida relacionado con riesgos para la salud.

Palabras clave-Degradación, Elementos de reconocimiento biológico, Metabolitos, Monitoreo Ambiental, Trazabilidad, aptámero.
\end{abstract}

\footnotetext{
${ }^{1}$ Producto derivado del proyecto de investigación "Investigación y desarrollo de aptasensores nanofotónicos para la cuantificación ultrasensible de contaminantes orgánicos persistentes en matrices acuosas medioambientales".

M. Torres, Universidad San Sebastián, Concepción, Chile, email: mtorresg@correo.uss.cl .

K. Pozo, Universidad San Sebastián, Concepción, Chile, karla.pozo@uss.cl.

V. Díaz, Universidad San Sebastián, Concepción, Chile, email: victor.diazg@uss.cl.
}

Como citar este artículo: Torres, M., Pozo, K. y Díaz, V. Influencia de la degradación del Clorpirifos en la detección analítica utilizando biosensores: revisión del estado actual y aspectos futuros, Entre Ciencia e Ingeniería, vol. 15, no. 30, pp. 9-21, julio-diciembre 2021.

DOI: https://doi.org/10.31908/19098367.2102.

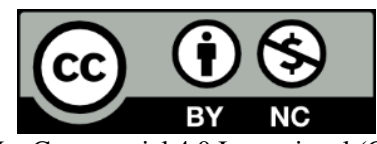

Attribution-NonCommercial 4.0 Intenational (CC By-NC 4.0)
Abstract - Chlorpyrifos (CP) is a widely used pesticide related to various health hazards, and for its ubiquity, its monitoring has become relevant to assess the state and rates of emission to the environment. On the other hand, environmental factors favor the degradation of $\mathrm{CP}$ and dissipation in the environment, making it difficult to trace and detect it in the different matrices. Nowadays, the use of biosensors provides promising analytical techniques for the detection of various environmental importance compounds. However, it is unknown if the natural degradation of these compounds would affect the correct recognition by biosensors, influencing their use as a traceability tool. The main objective of this review is to address the recent advances in biosensors for the detection of $\mathrm{CP}$, its challenges in detecting the real sample associated with the degradation of this pollutant, and the future aspects about with the environmental monitoring of this pesticide related to health risks.

Keywords - Degradation, Biological Recognition Elements, Metabolites, Environmental Monitoring, Traceability, Aptamer.

\section{ABREVIATURAS}

$\begin{array}{ll}\text { AchE } & \text { Acetilcolinesterasa } \\ \text { ADI } & \text { Ingesta diaria aceptable } \\ \text { ADN } & \text { Ácido desoxirribonucleico } \\ \text { AgNPs } & \text { Nanopartículas de Plata } \\ \text { ARN } & \text { Ácido ribonucleico } \\ \text { Au } & \text { Oro } \\ \text { AuNR } & \text { Nanorods de oro } \\ \text { AuNSs } & \text { Nano esferas de Oro } \\ \text { BChE } & \text { Butirilcolinesterasa } \\ \text { BDD } & \text { Diamante dopado con boro } \\ \text { BSA } & \text { Albúmina de suero bovino } \\ \text { BZE-DADOO } & \text { Benzoilecgonina-1,8-diamino-3,4-dioxaoctano } \\ \text { ChpA } & \text { Activación de transcripción } \\ \text { ChpR } & \text { Regulador de transcripción } \\ \text { cFLISA } & \text { Ensayo inmunoabsorbente unido a fluorescencia } \\ \text { CHTT } & \text { Quitosano } \\ \text { CdTe } & \text { El telururo de cadmio } \\ \text { CGE } & \text { Electrodo de carbono vítreo } \\ \text { COPs } & \text { Compuestos Orgánicos Persistentes } \\ \text { CP } & \text { Clorpirifós } \\ \text { CPO } & \text { Clorpirifós oxón } \\ \text { CS } & \text { Esferas de Carbono }\end{array}$




\begin{tabular}{|c|c|}
\hline C-SWCNT & $\begin{array}{l}\text { Nanotubos de carbono de pared simple } \\
\text { funcionalizadas con carboxilo }\end{array}$ \\
\hline $\mathrm{CuFe} 2 \mathrm{O} 4$ & Óxido de hierro de cobre \\
\hline $\mathrm{CuO} \mathrm{NF}$ & Nanocompuestos de cobre \\
\hline DETP & Ácido dietiltiofosfórico \\
\hline DFP & Fluorofosfato de diisopropilo \\
\hline DPV & Voltamperometría diferencial de pulsos \\
\hline dsCT & ADN genómico de timo de ternera de doble cadena \\
\hline ECD & Detector de captura de electrones \\
\hline EPA & Agencia de Protección Ambiental \\
\hline FGE & Enzima generadora de formilglicina \\
\hline FET & Transistor de efecto campo \\
\hline Fc@MWCN & $\begin{array}{l}\text { S Nanotubos de carbono multipared dispersos en } \\
\text { quitosano híbrido de ferroceno }\end{array}$ \\
\hline $\mathrm{fM}$ & Femtomolar \\
\hline FPD & Detector fotométrico de llama \\
\hline GC & Cromatografía de gases \\
\hline HAPs & Hidrocarburos aromáticos policíclicos \\
\hline HPLC & Cromatografía líquida \\
\hline $\mathrm{HRP}-\mathrm{Ab}$ & Anticuerpo policlonal \\
\hline HRMS & Espectrometría de masas de alta resolución \\
\hline IROX & Oxido de Iridio \\
\hline ITO & Óxido de indio y estaño \\
\hline Kow & Coeficiente de reparto octanol-agua \\
\hline Koc & Coeficiente de partición suelo-agua \\
\hline LOD & Límite de detección \\
\hline Log Kow & $\begin{array}{l}\text { Logaritmo del coeficiente de reparto octanol- } \\
\text { agua }\end{array}$ \\
\hline LOQ & Límite de cuantificación \\
\hline LMR & Límites máximos de residuos \\
\hline MAC & Valor promedio anual \\
\hline MIP & Polímeros de impresión molecular \\
\hline MOF & Estructuras metalorgánicas \\
\hline MS & Espectrómetro de masas \\
\hline MNP & Nanopartículas metálicas \\
\hline MUA & Ácido 11-mercaptomonomdecanoico \\
\hline MWCNTs & Nanotubos de carbono de paredes múltiples \\
\hline NF & Nanofiltración \\
\hline NPD & Detector nitrógeno-fósforo \\
\hline NPs & Nanopartículas \\
\hline $\mathrm{OH}$ & Hidroxilos \\
\hline OP & Organofosforados \\
\hline OMS & Organización Mundial de la Salud \\
\hline $\mathrm{OMC}$ & Carbono mesoporoso ordenado \\
\hline ONU & Organización de las Naciones Unidas \\
\hline PANI & Polianilina \\
\hline PATP & Poliaminotiofenol \\
\hline $\mathrm{PB}$ & Azul de Prusia (siglas en Ingles) \\
\hline PPy & Polipirrol \\
\hline PNPP & p-nitrofenil fosfato \\
\hline $\mathrm{Pt}$ & Platino \\
\hline PVS & Polivinil sulfonato \\
\hline QD & Puntos cuánticos \\
\hline SELEX & Selección in vitro \\
\hline $\mathrm{SiO} 2$ & Óxido de silicio \\
\hline SPE & Electrodo serigrafiado \\
\hline SWCNTs & Nanotubos de pared simple \\
\hline $\mathrm{TCP}$ & 3, 5,6-tricloro-2-piridinol \\
\hline TMP & 3, 5,6-tricloro-2-metoxipiridina \\
\hline UE & Unión Europea \\
\hline UPCL & Cromatografía líquida de ultra alta resolución \\
\hline USEPA & Agencia de Protección Ambiental de EEUU. \\
\hline UV & Ultravioleta \\
\hline
\end{tabular}

\section{INTRODUCCIÓN}

Dentro de las numerosas sustancias orgánicas que se conocen como contaminantes del agua, los plaguicidas son una fuente importante de contaminación tanto para aguas subterráneas como superficiales [1,2]. Se entiende por plaguicida a las sustancias de naturaleza química o biológica de carácter orgánico e inorgánico destinado al manejo y o control de plaga, incluidas especies no deseadas durante los procesos de producción y productos agrícolas [3] y abarca una amplia gama de productos químicos que incluyen insecticidas, fungicidas, rodenticidas, nematicidas, reguladores del crecimiento de las plantas, herbicidas y otros [4, 5,6]. Las propiedades químicas y físicas de los plaguicidas pueden diferir significativamente entre sí y en consecuencia su análisis y detección en matrices ambientales se transforma en un sistema complejo [6,7]. Si bien, los plaguicidas juegan un papel positivo para la economía de un país, su uso excesivo y generalizado ha deteriorado la biodiversidad $y$ en consecuencia impactos negativos en la calidad de los ecosistemas hídricos [8, 9, 10,11].

El destino de los plaguicidas en el ambiente se rige por los procesos de retención, transporte, disipación, degradación y sus interacciones en el medio ambiente, así también por las propiedades fisicoquímicas, solubilidad en agua, presión de vapor, coeficiente de partición suelo-agua $\left(\mathrm{K}_{\mathrm{oc}}\right)$, vida media, coeficiente octanol-agua $\left(\mathrm{K}_{\mathrm{ow}}\right)$ que simula el carácter hidrófobo de una sustancia que permite las estimaciones de concentración en los compartimientos ambientales. Además, existen otros factores que afectan la persistencia de los plaguicidas, en el medio ambiente tales como el contenido de materia orgánica, contenido de humedad, capacidad de infiltración y otros factores ambientales como el clima, temperatura, lluvia etc. [12,13].

El monitoreo de los plaguicidas en el medio ambiente tiene el potencial de orientar las directrices de gestión para regular las exposiciones a los plaguicidas que dañan la salud de las personas y otros organismos [14,15]. Con respecto al manejo de plaguicidas Citartan et al. [16] advierte que más del 95\% de los plaguicidas llegan a un destino que, no es necesariamente, la especie objetivo, lo que podría provocar la contaminación del agua y productos alimenticios.

Para el control y manejo apropiado de plaguicidas, la Organización Mundial de la Salud (OMS), la Organización de las Naciones Unidas (ONU), especializado en gestionar medidas de prevención a nivel mundial, y la Unión Europea (UE), han adoptado algunas políticas para permitir el manejo de plaguicidas y establecer niveles máximos de residuos (LMR) en productos agrícolas, alimentos y cuerpos de agua [17]. Los instrumentos legislativos vinculantes que regulan el uso de plaguicidas son: i) El Convenio de Estocolmo sobre Contaminantes Orgánicos Persistentes (COPs). ii) El Convenio de Róterdam sobre el procedimiento de aprobación a ciertos plaguicidas y otros productos químicos sobre el comercio internacional de plaguicidas y productos peligrosos iii) El Protocolo de Montreal sobre sustancias que agotan la capa de ozono. iv) Los Convenios de Basilea y Bamako sobre control de movimientos transfronterizos de residuos peligrosos y su eliminación. El clorpirifós al ser un plaguicida se regula su uso , transporte y concentración en matrices ambientales, 
así también, obtiene una importancia ambiental, por su presencia omnipresente en todas las matrices ambientales a pesar que en la actualidad no se encuentra clasificado como un compuesto orgánico persistente (COPs) se atribuye a su uso indiscriminado su permanencia en el medio ambiente, a sus características físico químicas y a la disminución de las capacidad asimilativa del medio ambiente para degradar al clorpirifós.

\section{CLORPIRIFÓS}

El clorpirifós (nombre IUPAC: O, O-dietil O-3, 5,6tricloropiridin-2-ilo- Fosforotioato) es compuesto clorado organofosforado Fig.1 de origen sintético, utilizado como insecticida de amplio espectro en la agricultura para el control de diversas plagas que afectan los cultivos como, por ejemplo, ácaros, insectos, huevos de insectos, larvas etc. [18].

El clorpirifós $(\mathrm{CP})$ es uno de los plaguicidas más usado a nivel mundial y su uso generalizado ha sido asociado con la contaminación de fuentes hídricas, suelos, aire, organismos no objetivos, contaminación de la atmósfera, el agua de lluvia y el agua de niebla $[14,19,20,21]$. La importancia de la contaminación del medio ambiente radica en que las personas pueden estar expuestas al clorpirifós a través de residuos químicos en alimentos y aguas de consumo, inclusive en los hogares, porque puede permanecer durante varios meses en lugares urbanos a causa de la privación de vectores que favorezcan su degradación [22].

El clorpirifós al ser uno de los plaguicidas más utilizados a nivel mundial ha acentuado las preocupaciones públicas y científicas sobre la seguridad alimentaria y medioambiental [23] dado que inhibe a la acetilcolinesterasa (AchE) y la butirilcolinesterasa (BChE), enzimas importantes en el funcionamiento del sistema nervioso y asociada a diversas enfermedades nerviosas. [24,25] información relevante, para cálculos de valoración por exposición a compuestos organofosforados [18,20,21,22,26], también el CP es potencialmente tóxico para los organismos incluidos las personas como daños que involucra trastornos neuronales, estrés oxidativo, daño en el ADN y endocrinos [19,27, 28,29].

El clorpirifós puede presentar moderada a prolongada persistencia ambiental, presentar degradación en el medio ambiente durante períodos de tiempo variables [30], sus productos de degradación Fig.2 más significativos corresponden a los metabolitos toxicológicamente relevantes de CP son: el 3,5,6-tricloro-2-piridinol (TCP), 3,5,6-tricloro-2metoxipiridina (TMP), O-etil-O-(3,5,6-tricloro-2- Piridilo) y Clorpirifós oxón (CPO). Algunas investigaciones han demostrado que el clorpirifós oxón (CPO) y el 3,5,6-tricloro2-piridinol (TCP) son más peligrosos en comparación con el compuesto principal, a causa de su estructura cíclica y de cloración en las posiciones 3,5,6 estructura similar a los compuestos organoclorados que presentan mayor toxicidad ambiental que los compuestos organofosforados [31].

Estudios señalan la presencia de al menos 143 plaguicidas incluido Clorpirifós y 21 productos de transformaciones en aguas subterráneas, que son la fuente más importante de suministro de agua potable en numerosos países incluido Chile [32], al mismo tiempo la escasez de agua dulce y su limitada disponibilidad a causado la necesidad de monitorear la calidad del agua para el consumo humano [29]. Donde, los datos que proporciona el monitoreo ambiental son fundamentales para evaluaciones y toma de decisiones y no expresan necesariamente una representación continua y completa del estado real de la matriz ambiental, dificultando la trazabilidad del proceso.

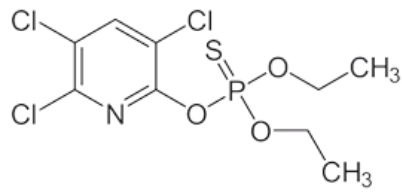

Fig. 1. Estructura química del clorpirifós (O, O-dietil O-3, 5,6tricloropiridina-2-ilo- Fosforotioato).
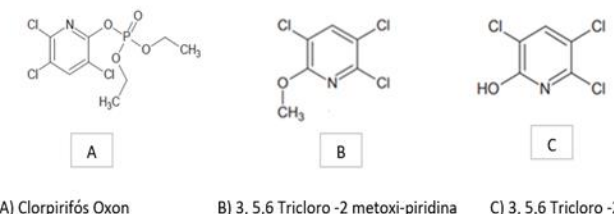

A) Clorpirifós Oxon

B) 3, 5,6 Tricloro -2 metoxi-piridina

C) 3, 5,6 Tricloro - 2 piridino

Fig. 2. Estructura química de los principales productos de degradación del Clorpirifós.

TABLA I

NORMAS DE CALIDAD AMBIENTAL PARA SUSTANCIAS PRIORITARIAS: CLORPIRIFÓS

\begin{tabular}{|c|c|c|c|}
\hline Matriz & Indicador $_{1}$ & Indicador $_{2}$ & Ente regulador \\
\hline $\begin{array}{l}\text { Las aguas superficiales } \\
\text { continentales } \\
\text { Ríos } \\
\text { Lagos } \\
\text { cuerpos de agua } \\
\text { artificiales }\end{array}$ & $\begin{array}{l}0.03 \mu \mathrm{g} / 1 \\
\text { Expresado como un } \\
\text { valor promedio } \\
\text { anual (MAC) }\end{array}$ & $\begin{array}{l}0.1 \mu \mathrm{g} / 1 \\
\text { Expresado como } \\
\text { una concentración } \\
\text { máxima permitida } \\
(\mathrm{MAC})\end{array}$ & $\mathrm{EU}, 2015-2018$ \\
\hline $\begin{array}{l}\text { Agua destinada al } \\
\text { consumo humano }\end{array}$ & $\begin{array}{l}30 \mu \mathrm{g} / \mathrm{L} \\
0.03 \mathrm{mg} / 1 \\
\text { Ingesta diaria } \\
\text { aceptable (ADI) }\end{array}$ & $\begin{array}{l}0,0001 \mathrm{mg} / 1 \\
\text { Máximo permitido }\end{array}$ & $\begin{array}{c}\text { Directiva } 98 / 83 / \mathrm{EC} \\
\text { sobre la calidad del } \\
\text { agua destinada a } \\
\text { consumo humano. } \\
\text { OMS } 2018\end{array}$ \\
\hline $\begin{array}{l}\text { Agua dulce } \\
\text { Agua salada }\end{array}$ & $\begin{array}{l}0.083-0.041 \mu \mathrm{g} / \mathrm{L} \\
\text { Criterio de calidad } \\
\text { del agua }\end{array}$ & $\begin{array}{l}0.011-0.0056 \\
\mu \mathrm{g} / \mathrm{L} \\
\text { Criterio de calidad }\end{array}$ & USEPA 1987 \\
\hline Frutas Cítricos & $\begin{array}{l}1,5 \mathrm{mg} / \mathrm{kg} \\
\text { limites máximos de } \\
\text { residuos (LMR) }\end{array}$ & & $\begin{array}{l}\text { Reglamento (UE) } \\
2018 / 686\end{array}$ \\
\hline $\begin{array}{l}\text { Algas y organismos } \\
\text { procariotas }\end{array}$ & $\begin{array}{l}0,01 \mathrm{mg} / \mathrm{kg} \\
\text { límites máximos de } \\
\text { residuos (LMR) }\end{array}$ & & $\begin{array}{l}\text { Reglamento (UE) } \\
2018 / 686\end{array}$ \\
\hline Leche de Vaca & $\begin{array}{l}0,02 \mathrm{mg} / \mathrm{kg} \\
\text { límites máximos de } \\
\text { residuos (LMR) }\end{array}$ & & $\begin{array}{c}\text { Reglamento (UE) } \\
2018 / 686\end{array}$ \\
\hline Frutas & $\begin{array}{l}0,01 \mathrm{mg} / \mathrm{kg} \\
\text { limites máximos de } \\
\text { residuos (LMR) }\end{array}$ & & $\begin{array}{c}\text { Reglamento (UE) } \\
2018 / 686\end{array}$ \\
\hline
\end{tabular}

El clorpirifós se encuentra en constante revisión por la EPA por los riesgos asociados a la salud humana y medio ambiente, siendo prohibido en algunos países de la UE. De acuerdo con sus características químicas es un compuesto que presenta volatilización intermedia, que le permite encontrarse en el medio ambiente en forma de vapor o adheridos a partículas atmosféricas y por tanto recorrer largas distancias antes de depositarse, como ocurre con su metabolito oxón en la atmósfera. Además, presenta baja solubilidad en agua y alta capacidad de adsorción en la materia orgánica $\left(\log \mathrm{K}_{\mathrm{ow}}=\right.$ 
4.78-5.11) logrando atravesar membranas biológicas y acumulación en lípidos [32]. Por esto, más la evidencia química intrínseca su presencia en el medio ambiente, respalda que el CP pueda considerarse un COPs, más aún el 3,5,6tricloro-2-piridinol (TCP) comparte semejanzas químicas y estructurales con el triclorofenol (TCP), precursor en la formación de Dioxinas y Furanos [33].

Pero, de acuerdo con los antecedentes antes señalados la presencia constante de clorpirifós en los compartimientos ambientales debido a su uso extensivo a nivel mundial que excedería la capacidad de los procesos químicos, físicos y biológicos que permitan una óptima degradación del $\mathrm{CP}$ en el medio ambiente.

\section{ESTÁNDARES DE CALIDAD AMBIENTAL}

Se han desarrollado programas para monitorear plaguicidas en aguas superficiales con el objetivo de reducir el impacto ambiental y resguardar los recursos hídricos. La UE, ha establecido valores máximos permitidos de concentraciones de plaguicidas para consumo de $0.1 \mathrm{mg} \mathrm{L}^{-1}$ y $0.5 \mathrm{mg} \mathrm{L}^{-1}$ respectivamente, que orienta los criterios de tolerancia, y máximos permitidos para $\mathrm{CP}$ en aguas y alimentos Tabla I con el objetivo de proteger la salud de las personas y la biodiversidad [34,35].

\section{ESTUDIOS DE DETECCIÓN DE CLORPIRIFÓS EN COMPARTIMIENTOS AMBIENTALES Y ALIMENTARIAS}

Los plaguicidas ingresan al medio acuático a través del uso de aguas residuales agrícolas, industriales y domésticas, en este contexto la contaminación por CP se refleja a través de su presencia y la de sus metabolitos en matrices ambientales bióticas y abióticas Tabla II. Pozo et al [36] ha descrito la presencia $\mathrm{CP}$ en aire en un estudio de variación estacional a nivel atmosférico en la región de la Araucanía, reportó variaciones de concentraciones de diez a miles de $\mathrm{pg} \mathrm{m}^{-3}(\sim 20-$ 14.600) en la atmósfera de Chile, del mismo modo, Cortés et al [37] informa concentraciones que varían de 444 a 14.624 $\left(\mathrm{pg} \mathrm{m}^{-3}\right)$ en la región del Maule, Chile, además Climent et al [38] reporta concentraciones del $\left(\sim 0.2 \mu \mathrm{gL}^{-1}\right)$ en aguas del río Cachapoal en Chile central Tabla II, así también Bhanti y Taneja [39],evaluaron residuos de clorpirifós en vegetales. Silipunyo [40] realizo un estudio para determinar los residuos de plaguicidas OP en frutas y verduras, durante el estudio, los residuos de CP eran los más comunes y estaban presentes en todas las muestras, así también en Chile se ha detectado Clorpirifós en numerosos productos principalmente en verduras y hortalizas [41]. Por otra parte, Hossain y col. [21] realizaron un estudio para monitorear los residuos de plaguicidas en muestras de agua y señala que en el $83 \%$ de las muestras se detectó presencia de clorpirifós en comparación con otros plaguicidas. La presencia de residuos de plaguicidas y sus productos de degradación en los recursos hídricos ha causado preocupación entre las autoridades a nivel mundial ya que se ha detectado en la fase disuelta y en partículas, concentraciones superiores a las establecidas por las legislaciones de diferentes países. Cruzeiro et al. [42]. A la luz de esta situación, se han desarrollado programas para monitorear plaguicidas en aguas superficiales para minimizar su impacto ambiental y proteger la calidad de los recursos hídricos [38, 43].

Otro factor de contaminación por $\mathrm{CP}$ es señalado por Bellas et al. [44] donde indica que el CP se absorbe en el polietileno (microplásticos), facilitando efectos tóxicos relacionados con la actividad biológica y cadenas tróficas marinas. A pesar de que los organofosforados son menos persistentes y tienen menos capacidad bioacumulativa, se ha detectado residuos de $\mathrm{CP}$ a nivel mundial en peces, aves, sangre humana, orina, animales, sedimentos, leche materna, etc. [45].

TABLA II

DETECCIÓN DE CLORPIRIFÓS EN DIFERENTES MATRICES (MUESTRAS)

\begin{tabular}{|c|c|c|c|}
\hline Matriz & $\begin{array}{c}\text { Concentraciones } \\
\text { detectadas }\end{array}$ & $\begin{array}{l}\text { Técnica de } \\
\text { detección }\end{array}$ & Referencias \\
\hline Aire & (20-14.600) pg m- ${ }^{3}$ & CG-MS & [36] \\
\hline Aire & $14.624,4 \mathrm{pg} / \mathrm{m}^{-3}$ & CG-MS & [37] \\
\hline Sedimentos & $6.33-560 \mathrm{ng} / \mathrm{g}$ & LC-MS-MS & [46] \\
\hline Lodos & $0.45-703 \mathrm{ng} / \mathrm{g}$ & & \\
\hline Suelos & $20.7-65.308 \mathrm{ng} / \mathrm{g}$ & & \\
\hline Agua de lago & $3.27-9.31 \mu \mathrm{g} / 1$ & HPLC & [20] \\
\hline $\begin{array}{l}\text { Sangre } \\
\text { humana }\end{array}$ & $0,00-0,49 \mathrm{mg} / \mathrm{L}$ & CG-ECD & [47] \\
\hline $\begin{array}{l}\text { Agua de mar - } \\
\text { atmosfera }\end{array}$ & $\begin{array}{c}1400-200 \mathrm{pg} \cdot \mathrm{m}^{-} \\
{ }^{2} \cdot \mathrm{d}^{-1}\end{array}$ & (GC-HRMS) & [48] \\
\hline Hortalizas & $0.00-3.47 \mathrm{mg} / \mathrm{kg}$ & $\begin{array}{l}\text { GC-FPD GC- } \\
\text { ECD }\end{array}$ & [49] \\
\hline Orina & $1.03 \mu \mathrm{g} / \mathrm{g}$ & UPLC-MS-MS. & {$[50]$} \\
\hline $\begin{array}{c}\text { Leche } \\
\text { pasteurizada }\end{array}$ & $0.085-0.355 \mathrm{mg} / \mathrm{L}$ & $\begin{array}{c}\text { GC-ECD GC- } \\
\text { MS/ }\end{array}$ & [51] \\
\hline Nueces & $7.2-77.2 \mu \mathrm{g} / \mathrm{kg}$ & $\begin{array}{l}\text { GC-FPD GC- } \\
\text { ECD }\end{array}$ & {$[52]$} \\
\hline Maíz & $\begin{array}{c}0.00-12.4 \mathrm{mg} \\
\mathrm{kg}-1\end{array}$ & GC-MS & {$[53]$} \\
\hline Agua de río & $\sim 0.2 \mu \mathrm{gL}-1$ & CG-MS & [38] \\
\hline Aire urbano & $\begin{array}{c}3-580 \mathrm{pg} \mathrm{m}^{-3}-3- \\
430 \mathrm{pg} \mathrm{m}^{-3}\end{array}$ & CG-MS & [54] \\
\hline Aire & $105.8 \mathrm{pg} \mathrm{m}^{-3}(*)$ & CG-MS & [22] \\
\hline $\begin{array}{c}\text { Tubería de } \\
\text { aguas }\end{array}$ & $0.5 \mathrm{ppb}(*)$ & Amperométrico & {$[55]$} \\
\hline Agua de riego & $0.012 \mathrm{mg} / \mathrm{kg}$ & CG-MS/MS & [14] \\
\hline $\begin{array}{l}\text { Agua y uvas } \\
\text { para vino }\end{array}$ & $0.6 \mathrm{~g} / \mathrm{ml}$ & $\begin{array}{l}\text { Espectroscopia de } \\
\text { reflectancia }\end{array}$ & [56] \\
\hline Agua de & $0.5 \mathrm{ng} \mathrm{L}^{-1}$ & CG-MS & [57] \\
\hline lluvia & $43 \mathrm{ng} \mathrm{L}^{-1}$ & & \\
\hline Lago & & & \\
\hline
\end{tabular}

(*) Detección de Clorpirifós oxón

\section{RUTAS DE DEGRADACIÓN DEL CLORPIRIFÓS Y PRODUCTOS DE TRANSFORMACIÓN}

La persistencia de los plaguicidas en un compartimiento ambiental depende de la eficiencia de los procesos de degradación naturales como biodegradación, fotodegradación e hidrolisis, donde los proceso pueden ocurrir bajo condiciones aeróbicas o anaeróbicas los cuales inducen, en algunos casos, a transformación con mayor toxicidad [58,59], 
estas transformaciones se realizan mediante reacciones de oxidación, reducción, ruptura nucleofílica o electrofílica y reorganización de los enlaces moleculares, mediadas por la actividad enzimática de microorganismos, la luz ultravioleta (UV) y el pH del ambiente, que actúan en simultáneo sobre los compuestos parentales $[22,60,61,22]$ reportándose vidas medias que fluctúan entre horas, días y meses condicionadas por procesos físicos, químicos y biológicos en el medio ambiente.

Los metabolitos generados de la degradación del clorpirifós en el medio ambiente son Fig. 3: i) Clorpirifósoxón (CPO), por oxidación de CP y generalmente se considera como el metabolito más tóxico ii) El 3, 5,6-tricloro-2-piridinol (TCP) y el ácido dietiltiofosfórico (DETP), principales productos de hidrólisis del Clorpirifós. iii) Otros productos de transformación de menor impacto ambiental como el O-etil-O(3, 5,6-tricloro-2-piridilo), ácido fosforotioico (fosforotioato) y 3, 5,6-tricloro-2-metoxipiridina (TMP) [11, 62,63].

El CPO y el TCP son los principales metabolitos cuando CP sufre fotólisis por radiación UV, presentando mayor solubilidad que $\mathrm{CP}$ y, por tanto, muestran una mayor movilidad de campo.[64]. En la atmósfera la degradación de $\mathrm{CP}$ indica la formación de CPO por oxidación en presencia de radicales hidroxilos $(\mathrm{OH})$, con vidas medias de 2 a 11 horas. [65]. De los diversos productos de transformación del clorpirifós, el TCP presenta mayor solubilidad y persistencia en agua siendo considerado por la EPA como un contaminante persistente, también asociado a la contaminación generalizada en suelos, cuando no está expuesto a luz. El TCP presenta persistencia a la degradación por microorganismos, limitando la biodegradación del clorpirifós por actividades antimicrobianas $[22,66]$.

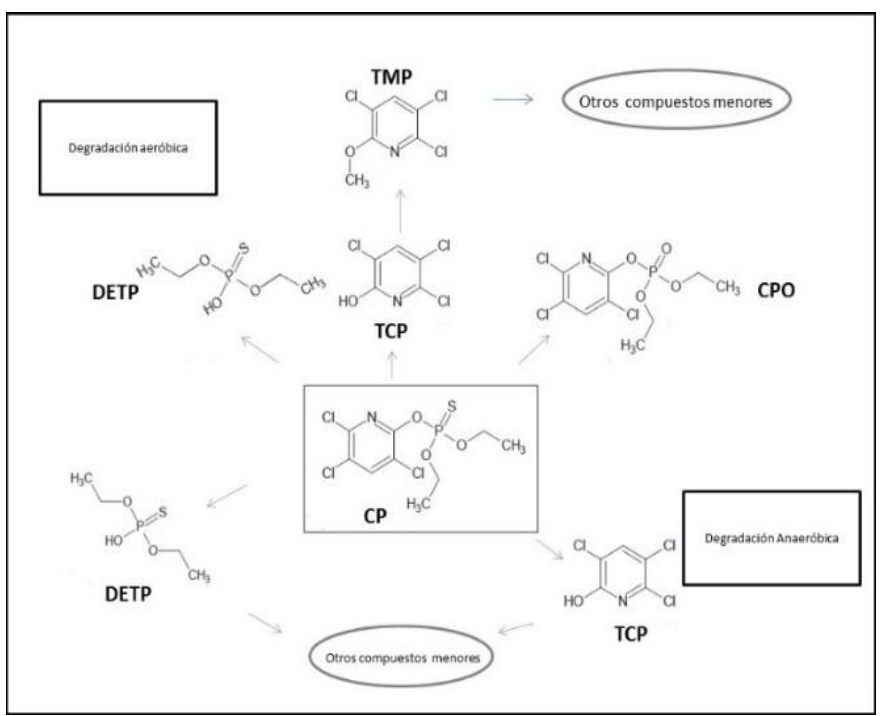

Fig. 3. Rutas principales de degradación del Clorpirifós en sistemas anaeróbicos y aeróbicos en presencia de microorganismos. CP (Clorpirifós), TCP (3, 5,6-Tricloro 2 Piridinol), DEPT (Dietil tiofosfato), CPO (Clorpirifós oxón), TMP (3, 5,6 Tricloro -2 metoxi-piridina).

Finalmente, a pesar de conocer la formas y vías de degradación de CP, su comportamiento en aguas superficiales se ve afectado por complejas interacciones de factores relacionados con su aplicación, condiciones climatológicas, condiciones fisicoquímicas y ciclos hidrológicos, por lo que el estudio de la presencia del CP en los sistemas acuáticos en diferentes niveles tróficos ha captado mayor interés los últimos años a causa de la creciente conciencia pública relacionados por la contaminación química [67]. Es relevante indicar los procesos generales de degradación y destino ambiental para el plaguicida Clorpirifós se relaciona a los procesos de disipación (pérdida de masa), degradación química y biológica, se presenta en la Fig. 5 Se indican las fracciones de degradación, la primera transformaciones mediante procesos bióticos donde el $\mathrm{CP}$ es degradado completamente, la segunda las transformaciones mediante procesos abióticos donde el $\mathrm{CP}$ es degrado parcialmente por procesos físicos y químicos, la tercera fracción corresponde al clorpirifós que no es transformado por los procesos descritos por tanto disponible ser identificado y detectados por los diferentes técnicas analíticas.

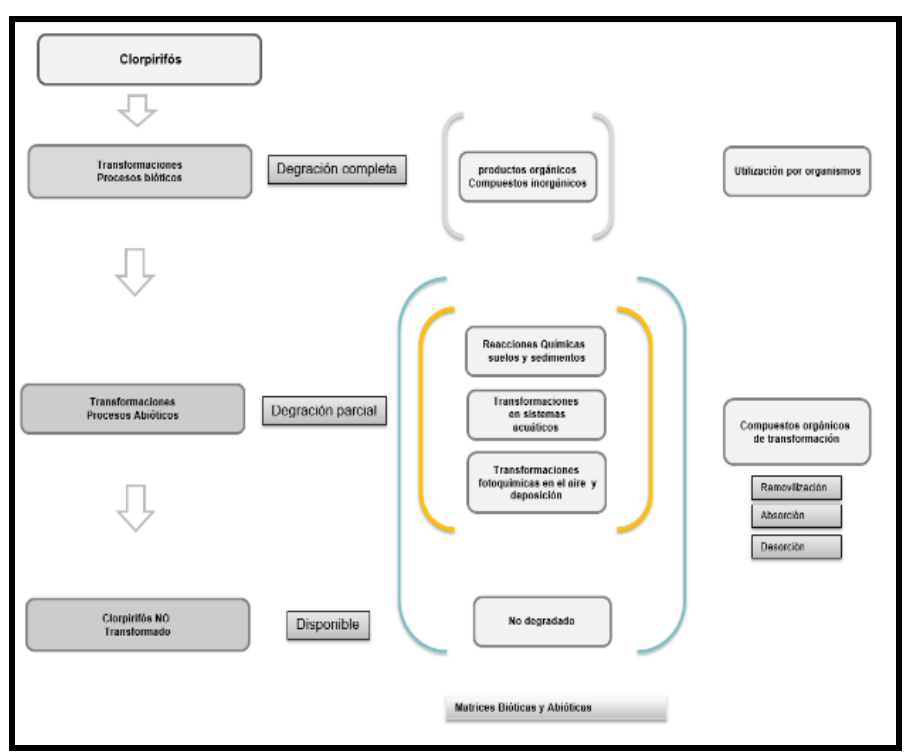

Fig. 4. Proceso general del destino ambiental de los compuestos organofosforados adaptado para Clorpirifós, modificado Kumar et al., (2018) y Dar et al., (2019).

\section{TÉCNICAS ANALÍTICAS PARA LA DETECCIÓN DE CLORPIRIFÓS}

Se han desarrollado muchas tecnologías analíticas para la detección de plaguicidas, como cromatografía líquida de alto rendimiento (HPLC) y cromatografía de gases (GC), las cuales tienen una alta sensibilidad y bajo límite de detección. En contraste con los atributos analíticos, los análisis suelen ser costosos, con tiempos extensivos de análisis y además requieren operadores capacitados para el manejo de los equipos $[28,68]$. En cambio, los biosensores son dispositivos biológicos y presentan atributos para el monitoreo de componentes residuales de plaguicidas en muestras ambientales 13]. A diferencias de las técnicas convencionales los biosensores se consideran herramientas bioanalíticas, de reconocimiento biológico que unido a un elemento transductor físico para la detección específica de un analito o múltiples analitos en respuesta a los desafíos de detección de 
compuestos tóxicos como estrategia económica, rápida y de uso en terreno [13].

\section{A. Técnicas analíticas Clásicas}

Para la detección de Clorpirifós existen técnicas analíticas de cromatografía de gases, cromatografía líquida de alto rendimiento, cromatografía de gases junto con espectrometría de masas y líquida. Métodos físicos de separación de componentes presentes en muestras ambiental que permite identificar y determinar la cantidad de un analito en la muestra. [36,37]. La detección de clorpirifós y sus productos de degradación se realiza a través de cromatografía de gases con detector fotométrico de llama (FPD), detector nitrógenofósforo (NPD) o detección de captura de electrones (ECD) ampliamente utilizados y aceptados para el análisis de residuos de plaguicidas. Otras técnicas analíticas que se han utilizado para detectar clorpirifós incluyen cromatografía de gases con detector de emisiones atómicas, sin embargo, las técnicas cromatografías requieren procedimientos de muestreos en terrenos, contenedores para tomas de muestras, almacenamientos adecuados, pretratamientos de las muestras, mayores volúmenes de solvente orgánicos, según del tipo de extracción 3540B y 3540C recomendados por la EPA.

Las principales diferencias y semejanzas de los métodos clásicos y las técnicas de biosensores para la detección de plaguicidas organofosforados se presentan en Tabla III, las ventajas comparativas se centran en la sensibilidad y especificidad de ambos métodos y las desventajas significativas en la falta de estandarización de los métodos analíticos basados en biosensores en comparación con las técnicas de cromatografía.

TABLA III

COMPARACION DE TECNICAS PARA LA DETECCIÓN DE CLORPIRIFÓS EN MATRICES AMBIENTALES

\begin{tabular}{|c|c|}
\hline \multicolumn{2}{|c|}{ Ventajas y desventajas } \\
\hline Técnicas clásicas & Técnica de biosensores \\
\hline Sensibilidad & Sensibilidad \\
\hline Especificidad & Especificidad \\
\hline $\begin{array}{l}\text { Estandarización de métodos } \\
\text { cromatográficos }\end{array}$ & $\begin{array}{c}\text { No hay estandarización del método por } \\
\text { biosensores }\end{array}$ \\
\hline Empleo de diferentes detectores & Uso de estándares de alta pureza \\
\hline Empleo de columna de diferente & Resultados cualitativos y cuantitativos \\
\hline polaridad & Requiere volúmenes menores de solventes \\
\hline Mayor tiempo de análisis & Menor tiempo de análisis \\
\hline Efectos de interferentes de la matriz & Efectos de interferentes de la matriz \\
\hline Uso de estándares de alta pureza & Uso en terreno \\
\hline Resultados cuantitativos & Empleo de diferentes elementos de \\
\hline Separación de los componentes & reconocimiento biológico \\
\hline $\begin{array}{l}\text { asociado a tiempo de retencion del } \\
\text { analito }\end{array}$ & La vida media de los biosensores es variable \\
\hline $\begin{array}{l}\text { Requiere de personal especializado } \\
\text { para el manejo de equipos }\end{array}$ & Presenta limitada aplicación comercial \\
\hline $\begin{array}{c}\text { Requiere extensos preanálisis de las } \\
\text { muestras }\end{array}$ & \\
\hline $\begin{array}{l}\text { Requiere uso de volúmenes mayores } \\
\text { de solventes }\end{array}$ & \\
\hline $\begin{array}{c}\text { Los equipos no se pueden usar en } \\
\text { terreno }\end{array}$ & \\
\hline
\end{tabular}

\section{B. Las técnicas analíticas de Biosensores}

Para la de detección de Clorpirifós se han descritos biosensores basados en enzimas y anticuerpos. En los últimos años se observa un aumento en el desarrollar de biosensores basados en aptámeros principalmente para evaluaciones de calidad alimentaria y progresos para la detección de residuos de clorpirifós en matrices ambientales. Los biosensores comerciales descritos para compuestos organofosforados pertenecen a métodos de screening como los kits de prueba de plaguicidas de la compañía RENEKABIO que utiliza el método de inhibición de la enzima colinesterasa, kit de detección de plaguicidas de la compañía ANP Health que utiliza el mismo método de inhibición y por último el kits NIDS ACE II de la compañía Charm Sciences Inc. permite realizar un barrido de residuos plaguicidas organofosforados en frutas y agua potable [69].

Los biosensores permiten detectar una multiplicidad de sustancias químicas y se compone de tres partes, un elemento de reconocimiento biológico que puede ser ácidos nucleicos, proteínas, enzimas, anticuerpos y aptámeros para el reconocimiento selectivo de un tipo o grupo de analitos de interés a una respuesta bioquímica, unida a un tipo de elemento transductor que se encarga de convertir la señal del reconocimiento biológico en señales cuantificables [70,71]

Los atributos de los biosensores es la alta estabilidad, especificidad para analitos tóxicos, detección rápida, precisión y reproducibilidad. Las principales ventajas es la posibilidad de monitoreo in situ, de medir contaminantes en matrices ambientales con una mínima cantidad de volúmenes de muestras, dar solución a la carga analítica y reducir los pretratamientos analíticos de las técnicas clásicas de detección $[28,72]$. Es preciso señalar que las moléculas de reconocimiento biológico juegan un papel fundamental en el avance de biosensores [7,26].

Los elementos de reconocimiento biológico más estudiados para Clorpirifós son las enzimas, anticuerpos, ácido nucleico, aptámeros y células enteras [73] y los elementos transductores se encuentra principalmente los electroquímicos, fluorescencia, potenciométrico, óptico y voltametría cíclica. En los últimos años la incorporación de nanomateriales ha permitido mejorar las capacidades de los biosensores, los nanomateriales comúnmente utilizados en la construcción de biosensores son sustancias compuestas de carbono, como los nanotubos y grafeno, puntos cuánticos (QD), polímeros artificiales y nanopartículas metálicas (MNP) por sus propiedades ópticas únicas, buena estabilidad fotoquímica, alta conductividad eléctrica, propiedad magnética, propiedades electroópticas que permiten una adecuada bioconjugación y amplificación de las señales bioquímica $(26,73,74]$.

Los elementos de reconocimiento biológico descritos para la construcción de biosensores para clorpirifós se individualizan en Tabla IV se exhibe las ventajas y desventajas de cada elementos de reconocimiento para la detección de compuestos orgánicos fosforados, destacan los aptámeros que son nucleótidos de ARN, DNA, modificados que se aíslan de una biblioteca de oligonucleótidos mediante un proceso de selección in vitro, mediante enriquecimiento exponencial (método SELEX), presentan una elevada afinidad, especificidad $y$ se pueden adquirir con las 
propiedades y/o modificaciones deseadas para análisis específicos de contaminantes [28].

De igual forma los anticuerpos presentan varios atributos y a menudo son utilizados como método de detección en seguridad alimentaria, monitoreo ambiental y diagnósticos clínicos [73]. Los anticuerpos pueden ser policlonales, es decir, de diferentes líneas de células o monoclonal de una sola fuente celular, estos últimos son más selectivos en comparación con anticuerpos policlonales por las uniones de afinidad que se producen, además las desventajas de los anticuerpos es que muestran sensibilidad a la temperatura y a la desnaturalización, por tanto, tiene una vida analítica limitada y dificultad para realizar análisis en muestras acuosas [72,75].

El elemento de reconocimiento biológico descrito de forma habitual para biosensores son las enzimas como la acetilcolinesterasa (AChE), butirilcolinesterasa (BChE), Tirosinasa y Fosfatasa, que permite la detección de una familia de compuestos orgánicos fosforados y carbamatos, basado en la acción de la enzima acetilcolinesterasa (AChE) [76,77]. La desventajas más significativa es la selectividad para Clorpirifós, porque en matrices ambientales la actividad enzimática se ve afectada por otros compuestos orgánicos como los piretroides, las triazinas, diferentes hidrocarburos aromáticos policíclicos (HAPs) y por compuestos inorgánico que interfieren e inhiben la actividad enzimática como los metales pesados, iones metálicos, como $\mathrm{Hg}^{2+}, \mathrm{Cd}^{2+}, \mathrm{Cu}^{2+} \mathrm{y}$ $\mathrm{Pb}^{2+}$ por tanto, la presencia de iones y otros compuestos tóxicos son las principales limitaciones para el uso de enzimas en muestras ambientales [34,70,78].

TABLA IV

ELEMENTOS DE RECONOCIMIENTO BIOLÓGICO PARA LA DETECCIÓN DE CLORPIRIFÓS

\begin{tabular}{|l|l|l|l|l|}
\hline Aptámeros & Enz imas & Célu las & Anticuerpos & Ref. \\
\hline Vida útil & Vida útil limitada. & Vida útil limitada. & Alta constante de & {$[79]$} \\
prolongada. & Respuesta rápida y & Elevada actividad. & unión anticuerpo- & {$[80]$} \\
Fácil & variedad de enzimas. & Respuesta lenta en & analito. & {$[81]$} \\
modificación para & Sensibilidad frente a & comparación con las & Vida útil limitada & {$[34]$} \\
mejorar su & condiciones & enzimas. & Sensibilidad y & {$[82]$} \\
funcionalidad. & fisiológicas & Baja sensibilidad. & selectividad elevada. & \\
Mayor estabilidad & Estabilidad limitada & Específico para una & Dificultad para & \\
en comparación & por parámetros & clase de compuesto. & operar en medios & \\
con los elementos & fisicoquímicos. & & acuosos. & \\
biológicos. & Selectivo para una & & En ocasiones & \\
Síntesis rápida en & familia de & & requiere marcaje. & \\
comparación con & compuestos. & & Producción in vivoy & \\
los anticuerpos. & Disponibilidad & & se desnaturalizan & \\
Específico para & comercial. & & & \\
cada analito. & & & & \\
\hline
\end{tabular}

De forma similar los biosensores basados en células enteras son métodos de screening para la detección de contaminantes organofosforados como el clorpirifós, porque se evalúa el estado metabólico de la célula y la viabilidad celular como señales cuantificables. La desventaja que no es método específico para un compuesto en particular como el clorpirifós [83].

\section{BIOSENSORES PARA CLORPIRIFÓS}

Los biosensores descritos para Clorpirifós en su gran mayoría corresponde a biosensores enzimáticos, como el reportado por Wei et al.[84,] para compuestos organofosforados incluido el clorpirifós utilizando un biosensor basado en acetilcolinesterasa y un electrodo de diamante dopado con un metaloide como el Boro modificado con AuNPs y esferas de carbono (AChE/AuNPs-CSs/BDD) informó, el efecto inhibidor del Clorpirifós para rangos de concentración del orden $10^{-11}$ a $10^{-7} \mathrm{M}$ y un límite de detección de $1.3 \times 10^{-13} \mathrm{M}$, en muestras de jugo de pepino utilizando el método de adición estándar incluyendo pruebas de recuperación del método del orden del $91.2 \%$, el autor recomienda el biosensor enzimático para el monitoreo de organofosforados en muestras ambientales. De forma similar, Rodríguez et al.[85] presentó una metodología para la identificación de clorpirifós en aguas de consumo y leche, para ello utilizó un biosensor amperométrico para la expresión inhibidora de la enzima acetilcolinesterasa (AChE), inmovilizada a través de la técnica de reticulación que implica el uso de reactivos bifuncionales para generar enlaces intermoleculares entre la enzima y el transductor con el objetivo de mejorar la señal biológica a detectar, las concentración de clorpirifós se encontraron en el rango de $1,0 \times 10^{-6} \mathrm{M}$ a 5,0 $\times 10^{-2} \mathrm{M}$ y límite de detección de 5,0 x $10^{-6} \mathrm{M}$. Las muestras de agua enriquecidas exhibieron recuperaciones del orden de $-93.98 \%$ sin embargo, en las muestras de leche las recuperaciones analíticas obedecieron a valores 82,81\% atribuido al efecto de la matriz, la concentración de clorpirifós informada en muestras de agua fue de 5,11 x $10^{-6} \mathrm{M}$, la técnica analítica se comparó con la técnica de cromatografía de gases concluyendo que la funcionalidad del método como screening y que la cantidad de enzima a utilizar es un factor crítico para la detección CP. En un enfoque similar Halamek et al. [86] describe un biosensor piezoeléctrico de alta sensibilidad basado en el complejo AChE-BZE-DADOO la técnica a desarrollar correspondió a una solución conjugada de MUA-TNTU que permite vincular las moléculas sensoras con grupos actuando como monocapa auto ensamblado de yoduro de acetilcolinesterasa como sustrato para la detección de 4 insecticidas organofosforados inhibidores de colinesterasa; el Fluorofosfato de diisopropilo (DFP), Paraoxón, clorpirifós y Clorfenvinfos, reporta un el límite de detección del biosensor para clorpirifós de $1 \times 10^{-7} \mathrm{~mol} \mathrm{~L}^{-1}$ en ensayos de laboratorio, sin embargo el biosensor descrito para el análisis de muestras de río no informa concentraciones de CP detectadas en la muestra ambiental, atribuida al efecto de la matriz y complejidad intrínseca del CP relacionado con la baja solubilidad del clorpirifós en agua.

De manera similar Cao et al. [87] elaboró un Inmunosensor electroquímico de impedancia para la detección de $\mathrm{CP}$ en el cual se inmoviliza un anticuerpo monoclonal anti-clorpirifós sobre la superficie de un microelectrodo de oro $(\mathrm{Au})$, los cambios de impedancia indicaron un límite de detección para clorpirifós de $1.4 \times 10^{-5}$ $\mu \mathrm{g} \mathrm{mL}{ }^{-1}$ y selectividad del inmunosensor frente a otros plaguicidas como el grupo químico de los carbamatos, Foxim y otro plaguicida organofosforados, en este estudio se informó un límite de detección de $0.014 \mathrm{ng} \mathrm{ml}^{-1}$ en muestras de vegetales enriquecidas con $\mathrm{CP}$ y la influencia de la matriz en los resultados de detección del inmunosensor para Clorpirifós. 
De la misma manera, con el objetivo de evaluar residuos de CP en alimentos, Jiao et al. [34] desarrollo un aptasensor para Clorpirifós basado en Carbono mesoporoso-Ferroceno de nanotubos de Carbono de pared múltiple (Fc@MWCNTsCS) para cuantificar clorpirifós a través de voltametría, el aptámero presentó selectividad para el clorpirifós en extractos de verduras enriquecidos y un límite de detección de $3,33 \times 10^{-4} \mu \mathrm{g} \mathrm{mL}^{-1}$ y se evalúo su selectividad frente a otros plaguicidas organofosforados y carbamatos como el Carbofurano, Diclorvos, Metil Paration y Foxim, el autor señala que la incorporación de nanomateriales incrementa la conductividad y la sensibilidad del método, además de las tasa de recuperación del método de $106 \%$ lo que indicaría que aptasensor tiene un elevado potencial de aplicación ambiental.

De manera análoga Xu et al. [88] desarrollo un aptasensor voltametríco específico para Clorpirifós de nanocompuestos de cobre (CuO NF) y nanotubos de carbono de pared simple funcionalizadas con carboxilo (C-SWCNT) para mejorar la capacidad de inmovilización, los resultados presentados señalan una buena linealidad para clorpirifós en un rango de 0.1 - $150 \mathrm{ng} \mathrm{mL}^{-1}$ y un límite de detección de $70 \mathrm{pg} \mathrm{mL}^{-1}$ en muestras de vegetales, también se evaluó la selectividad en presencia de otros plaguicidas organofosforados y fungicidas. El tratamiento en muestras reales se desarrolló mediante adición estándar y bajo la evaluación de interferentes de la matriz e indicadores de recuperación del método.

Igualmente Doushani et al. [89] describe un aptasensor electroquímico para Clorpirifós basado en un electrodo de carbono vítreo modificado con un polímero electropolimerizado impreso con aptámeros y de oro (AuNR), para muestras de frutas y verduras, el método utilizado es de adición estándar y los plaguicidas interferentes para evaluar selectividad utilizados fueron Dimetoato, Carbofurano y Malatión, las concentraciones informadas se encuentran en el rango de 1.0 fM - 0.4 pM, e indica un límite de detección es $0.35 \mathrm{fM}$ de CP para muestras enriquecidas con el plaguicida.

Capoferri y col. [90] desarrolló un sensor basado en nanomateriales utilizando un electrodo serigrafiado de óxido de estaño modificado con NPs IrOx y con un polipirrol impreso usando voltamperometría cíclica y polímeros de impresión molecular (MIP), se plantea como transductor fisicoquímico el óxido de Iridio a nanoescala unido al polímero de impresión molecular como capa de reconocimiento para la detección de $\mathrm{CP}$ el polímero orgánico en presencia de clorpirifós, permite la detección visual utilizando un teléfono inteligente, las imágenes generadas se utilizaron para cuantificar el $\mathrm{CP}$ a través del cambio de color visual de transparente a azul-negro vinculado con las concentración de clorpirifós ,el sensor presento un rango dinámico de los $100 \mathrm{fM}$ y $1 \mathrm{mM}$. Los compuestos utilizados para evaluar selectividad química presentaron respuestas analíticas entre el 15-22 \% (Diclorvos y Clorfenvinfos) del mismo modo se ejecutó un análisis en muestras de agua potable enriquecidas con el pesticida y la técnica alcanza porcentajes de recuperación en el rango de los $94 \%$ indicando viabilidad del sensor para muestras reales, indicando un límite de detección de $0.1 \mathrm{pM}$.

La investigación de los avances bioanalíticas para la detección de clorpirifós con frecuencia describen la incorporación de nanomateriales como elementos transducción y las ventajas de los elementos de reconocimiento biológico unido parámetros analíticos de calibración como la repetibilidad y reproducibilidad de los métodos de biosensores, como uso de estándares de alta pureza, rangos de linealidad, límites de detección y técnicas de adición interna en muestras ambientales para evaluar calidad alimentaria y la detección de $\mathrm{CP}$ en aguas consumo humano, así también dar respuesta a la necesidad de monitoreo, análisis analíticos rápidos y de uso en terreno. Otro parámetro que se describe los avances de biosensores es la selectividad para clorpirifós comparado con plaguicidas de diferente estructura química y peso molecular, sin embargo, no hay estudios de selectividad que compare la selectividad del clorpirifós y sus metabolitos ambientales como parámetro de calidad de los métodos de biosensores analíticos. Finalmente, la incorporación reciente de elementos de reconocimiento molecular de materiales sintéticos surge como una alternativa a las desventajas de los elementos de reconocimiento biológico para la detección de Clorpirifós.

Diferentes autores especifican biosensores para la detección de clorpirifós Tabla V, el 44\% de las revisiones de biosensores ambientales se basan en enzimas como elemento de reconocimiento biológico, seguido de $22 \%$ de los biosensores que utilizan anticuerpos y por último los biosensores basados en aptámeros representan el 15\% de los estudios para Clorpirifós para esta revisión, en cuanto a los sistema de transductor para clorpirifós los biosensores electroquímicos representan el $66 \%$ de los estudios para clorpirifós unido a diferentes nanomateriales, en cuanto a las unidades de concentraciones reportadas en alimentos y ensayos de laboratorio en muestras ambientales se expresan en el rango de picomolar y nanomolar. Los parámetros de validación se centran en la selectividad, especificidad, análisis de recuperación analítica en términos de concentración, repetitividad del método, límite de detección (LOD) y límite de cuantificación (LOQ), así también, rangos lineales, rangos de estabilidad en términos de mantención de los bioelementos y estabilidad de análisis, sin embargo, la detección del CP en matrices ambientales sigue siendo un gran desafío. En este sentido los esfuerzos de técnicas de monitoreo ayudarán a desarrollar medidas apropiadas para controlar contaminantes de uso excesivo y minimizar los riesgos para la salud de las personas [28]. 
TABLA V

REVISIÓN DE ELEMENTOS DE RECONOCIMIENTO BIOLÓGICO PARA CLORPIRIFÓS

\begin{tabular}{|c|c|c|c|c|c|}
\hline $\begin{array}{l}\text { Elemento de } \\
\text { reconocimiento }\end{array}$ & Composición del biosensor & Mecanismo de detección & Rango lineal & $\begin{array}{l}\text { Límite de } \\
\text { Detección }\end{array}$ & Ref. \\
\hline Enzimas & AgNPs & Amperometría & $1.0 \times 10^{-13}-1 \times 10^{-8} \mathrm{M}$ & $5.3 \times 10^{-14} \mathrm{M}$ & [91] \\
\hline Enzimas & MOF / enzima AChE /AuNPs oro. & $\begin{array}{l}\text { voltamperometría } \\
\text { amperometría }\end{array}$ & $10-100 \mathrm{ng} / \mathrm{L}$. & 6ng / L & [92] \\
\hline Enzimas & óxido de grafeno óxido reducido Circonio & Amperometría & $\begin{array}{l}0.1-10^{3} \mathrm{pM} \\
1.0-10^{5} \mathrm{nM}\end{array}$ & $0.1 \mathrm{pM}$ & [93] \\
\hline Enzimas & óxido grafeno Reducido & Fotoelectroquímica & $1.0-1000 \mu \mathrm{g} \mathrm{L}^{-1}$ & $1.0-1000 \mu \mathrm{g} \mathrm{L}^{-1}$ & [91] \\
\hline Enzimas & $\begin{array}{c}\text { Grafeno puntos cuánticos } \mathrm{CuFe}_{2} \mathrm{O}_{4} / \text { magnético } \\
\text { nanocristales de racimos }\end{array}$ & Fotoelectroquímica & $1.0-10^{3} \mu \mathrm{g} \mathrm{L}^{-1}$ & $0.3 \mu \mathrm{g} \mathrm{L}^{-1}$ & {$[94]$} \\
\hline Enzimas & $\begin{array}{c}\text { Nanotubo de carbono de paredes múltiples } \\
\text { (MWCNTs) }\end{array}$ & Voltametría & $0.001-50 \mu \mathrm{g} \mathrm{L}^{-1}$ & $1.0 \mu \mathrm{g} \mathrm{L}^{-1}$ & {$[95]$} \\
\hline Enzimas & NPs Óxido de zinc & Voltametría & $0.1-10^{3} \mathrm{pM}$ & $0.05 \mathrm{pM}$ & {$[96]$} \\
\hline Enzimas & $\begin{array}{c}\text { PB-modificado/SPE Co-ftalocianina y electrodos } \\
\text { serigrafiados modificados con azul de Prusia } \\
\text { (SPE) Clorpirifos-metil oxon* }\end{array}$ & Amperometría & $0.5-2 \mathrm{ppb}$ & $0.5 \mathrm{ppb}$ & {$[97]$} \\
\hline Enzimas & Electrodos de grafito* & Amperometría & - & $0.1 \mathrm{ppb}$ & {$[98]$} \\
\hline Enzimas & $\begin{array}{l}\text { Sensor basado en material compuesto de } \\
\text { nanoestructura de carbono-quitosano }\end{array}$ & Voltametría & $10^{-10}-10^{-7} \mathrm{M}$ & $1.58 \times 10^{-10} \mathrm{M}$ & [99] \\
\hline Enzimas & Nanopartículas Platino & Amperometría & $0.25-10 \mu \mathrm{g} \mathrm{L}^{-1}$ & $0.2 \mu \mathrm{g} \mathrm{L}^{-1}$ & [100] \\
\hline Enzimas & $\begin{array}{c}\text { El biosensor de papel está incrustado con lipasa y } \\
\text { palmitato de p-nitrofenol (PNPP) }\end{array}$ & $\begin{array}{l}\text { Aplicación móvil } \\
\text { Androide y análisis } \\
\text { basado en PoC }\end{array}$ & $0.1-1.0 \mathrm{mg} \mathrm{L}^{-1}$. & $0.065 \mathrm{mgL}^{-1}$ & [101] \\
\hline Anticuerpos & $\begin{array}{l}\text { BSA/anticlorpirifós /AuNPs/PANI/ } \\
\text { MWCNTs/ CHIT/ GCE }\end{array}$ & Voltametría & $0.1-1.0^{5} \mathrm{ng} \mathrm{mL}^{-1}$ & $0.046 \mathrm{ng} \mathrm{mL}^{-1}$ & [102] \\
\hline Anticuerpos & $\begin{array}{l}\text { biosensor fluorescente inmunocromatográfico } \\
\text { (NPs) }\end{array}$ & Fluorescencia & $1-50 \mathrm{ppb}$ & $1.0 \mathrm{ppb}$ & [7] \\
\hline Anticuerpos & MWCNTs tionina quitosano DPV & Voltametría & $0.1-10^{-5} \mathrm{ppb}$ & $0.046 \mathrm{ppb}$ & [102] \\
\hline Anticuerpos & BSA-Ag/Pt/SiO $2 / \mathrm{HRP}-\mathrm{Ab}$ & Amperometría & $0.4-20 \mathrm{ng} \mathrm{mL}^{-1}$ & $22.6 \mathrm{ng} \mathrm{mL}^{-1}$ & {$[84]$} \\
\hline Anticuerpos & QDs/ (cFLISA) & Fluorescencia & $15.2-205.5 \mathrm{ng} \mathrm{mL}^{-1}$ & $8,4 \mathrm{ng} \mathrm{ml}^{-1}$ & [103] \\
\hline anticuerpos & FET de grafeno & Potencial eléctrico & $1,8 \mathrm{fM}-100 \mathrm{pM}$ & $1,8 \mathrm{fM}$ & [104] \\
\hline $\mathrm{ADN}$ & dsCT/DNA/ePPy/PVS/ITO & Voltametría & $0.0016-0.025 \mathrm{ppm}$ & $0.0016 \mathrm{ppm}$ & [105] \\
\hline $\mathrm{ADN}$ & dsCT/DNA atrapamiento PANI/PVS/ITO & Voltametría & - & $0.5 \mathrm{ppb}$ & [106] \\
\hline $\begin{array}{l}\text { Reemplazo de } \\
\text { Ligandos }\end{array}$ & CdTe/ QDs. & Fluorescencia & $0.1 \mathrm{nM}-10 \mu \mathrm{M}$ & $\sim 0.1 \mathrm{nM}$ & [107] \\
\hline- & PATP / AuNPs & voltametría & - & $115.69 \mathrm{ppb}$ & [108] \\
\hline Aptámeros & Ag-NanoZyme & Espectroscopia & $35-210 \mathrm{ppm}$ & $11.3 \mathrm{ppm}$ & [109] \\
\hline aptámeros & (QDs-AuNSs) & Fluorescencia & - & $0,73 \mathrm{ng} \mathrm{mL}^{-1}$ & [110] \\
\hline Aptámeros & Fc@MWCNTs/OMC/GCE & Voltametría & $0.1-10^{5} \mathrm{ng} \mathrm{mL}^{-1}$ & $0.033 \mathrm{ng} \mathrm{mL}^{-1}$ & {$[28]$} \\
\hline Aptámeros & Nanocompuesto CuO/ NFs-SWCNTs. & Voltametría & $0.1 \mathrm{a} 150 \mathrm{ng} \mathrm{mL}^{-1}$ & $70 \mathrm{pg} \mathrm{mL}^{-1}$ & {$[88]$} \\
\hline Células & $\begin{array}{l}\text { chpA/ ChpR/ Escherichia coli } \\
\text { (FGE)/ }\end{array}$ & Fluorescencia & $25-500 \mathrm{nM}$ & & [111] \\
\hline
\end{tabular}




\section{PERSPECTIVAS Y DESAFÍOS DE DETECCIÓN DE CLORPIRIFÓS EN MUESTRAS AMBIENTALES}

El progreso de nuevas tecnologías analíticas reconoce las limitaciones de las técnicas analíticas clásicas y da respuesta a ellas a través de técnicas de reconocimiento biológico unido a un elemento de transducción para el monitoreo ambiental de compuestos sintéticos y tóxicos como el clorpirifós en el medio ambiente. Esta revisión bibliográfica al igual que Weerathunge et al. [105] expresa la importancia de desarrollar nuevas tecnologías analíticas para la detección de contaminantes en aguas y dar cumplimiento regulaciones ambientales de compuestos organofosforados como el Clorpirifós en términos de especificidad, análisis rápidos, en terreno y menor costo de análisis en comparación con las técnicas clásicas.

Se puede observar que se han logrado avances en el área analítica basados en ensayos de laboratorio para la detección de CP a concentraciones femtomolar (fM) utilizando aptasensores y que la incorporación de nanomateriales ha permitido mejorar y optimizar las señales analíticas para Clorpirifós.

El desafío importante en el desarrollo de biosensores para Clorpirifós es el efecto de la degradación en su detección analítica, por tanto, evaluar cómo influye la degradación total y parcial del compuesto en una matriz ambiental es un desafío analítico que considerar en futuros estudios.

Desde una mirada ambiental desarrollar estrategias y metodologías de detección analítica para CP en el medio ambiente, además, de considerar las propiedades químicas intrínsecas del $\mathrm{CP}$ se debe incluir la dinámica del compuesto en el medio ambiente y sus interacciones para la elección eficiente del elemento de reconocimiento biológico para el desarrollo de biosensores ambientales.

Desde el punto de vista analítico la atención de las técnicas de biosensores para la detección de $\mathrm{CP}$ en el área ambiental aún es un desafío debido a estabilidad física de los elementos de reconocimiento biológico y de la vida útil de los biosensores para el monitoreo de clorpirifós.

Otro desafío de las técnicas de biosensores es la estandarización de los análisis de biosensores para los compuestos organofosforados en comparación con las técnicas clásicas de detección.

Los elementos de reconocimiento biológico como los aptámeros presentan atributos sobresalientes frente a los anticuerpos, células y enzimas para clorpirifós en términos de selectividad, reproducibilidad y estabilidad frente a factores ambientales para el monitoreo y detección, sin embargo, aún es un desafío por explorar la selectividad del aptámeros para clorpirifós frente a sus metabolitos en muestras reales.

\section{CONCLUSIONES}

El clorpirifós ha llamado el interés global, por ser uno plaguicidas más usados a nivel mundial, ocasionando la contaminación de diversos cuerpos de agua y alimentos de consumo. Por esta razón, avanzar en el desarrollo de nuevas tecnologías que permitan una oportuna detección ambiental y trazabilidad es uno de los hitos importantes en el área de la química ambiental y salud pública.

Considerar la complejidad de detección de residuos de $\mathrm{CP}$ en muestras de aguas de consumo y las variaciones de degradación de $\mathrm{CP}$ es una de las limitaciones más importante que abordar para su identificación ambiental.

Esta revisión comprueba que los biosensores son una alternativa a la detección de clorpirifós, sin embargo, aún no hay biosensores certificados para estudios ambientales que obedezcan a la necesidad de monitoreo de compuestos tóxicos con efectos nocivos en salud pública.

En cuanto a los elementos de reconocimiento biológico para la detección de clorpirifós. Los aptámeros, en términos analíticos, presentan las mayores virtudes, evidenciado por su mayor estabilidad química, favoreciendo su uso en terreno para el monitoreo ambiental. Pero, surge una nueva incertidumbre, si los aptámeros tienen la capacidad de distinguir al CP del CP parcialmente degradado en el medio ambiente o si, la similitud de estructura química con sus metabolitos y otros compuestos orgánicos en el medio ambiente se vuelve un interferente para su detección. Por lo que avanzar en determinar si la degradación natural del CP afecta su identificación en muestras ambientales a través del uso de herramientas analíticas como los biosensores, se vuelve crucial.

Finalmente, no todos los biosensores permiten detectar clorpirifós en las concentraciones que se requiere en matrices acuosas y que permita su caracterización de acuerdo con las normas internacionales vigentes.

\section{AGRADECIMIENTOS}

Se agradece el apoyo financiero del proyecto FONDECYT N³190734 Postdoctorado.

\section{REFERENCIAS}

[1] R. H. Coupe and J. D. Blomquist, "Water-soluble pesticides in finished water of community water supplies," J. / Am. Water Work. Assoc., vol. 96, no. 10, pp. 56-68, 2004.

[2] Q. Zhang, S. Zheng, S. Wang, W. Wang, H. Xing, and S. Xu, "Chlorpyrifos induced oxidative stress to promote apoptosis and autophagy through the regulation of miR-19a-AMPK axis in common carp," Fish Shellfish Immunol., vol. 93, no. July, pp. 1093-1099, 2019.

[3] F. Edition, "Manual on development and use of FAO and WHO specifications for pesticides Second Revision Available only on the Internet," no. November 2010.

[4] S. Akhtar, S. T. S. Gilani, and N. Hasan, "Persistence of chlorpyrifos and fenpropathrin alone and in combination with fertilizers in soil and their effect on soil microbes," Pakistan J. Bot., vol. 36, no. 4, pp. 863 $870,2004$.

[5] E. M. John and J. M. Shaike, "Chlorpyrifos: pollution and remediation," Environ. Chem. Lett., vol. 13, no. 3, pp. 269-291, 2015.

[6] P. C. Mane et al., "Highly sensitive label-free bio-interfacial colorimetric sensor based on silk fibroin-gold nanocomposite for facile detection of chlorpyrifos pesticide," Sci. Rep., vol. 10, no. 1, pp. 1-14, 2020.

[7] M. Cycoń, M. Wójcik, and Z. Piotrowska-Seget, "Biodegradation of the organophosphorus insecticide diazinon by Serratia sp. and Pseudomonas sp. and their use in bioremediation of contaminated soil," Chemosphere, vol. 76, no. 4, pp. 494-501, 2009.

[8] S. Liu, Z. Zheng, and X. Li, "Advances in pesticide biosensors: Current status, challenges, and future perspectives," Anal. Bioanal. Chem., vol. 405, no. 1, pp. 63-90, 2013. 
[9] C. J. Vörösmarty et al., "Global threats to human water security and river biodiversity," Nature, vol. 467, no. 7315, pp. 555-561, 2010.

[10] S. L. Pimm et al., "The biodiversity of species and their rates of extinction, distribution, and protection," Science (80), vol. 344, no. 6187,2014

[11] R. Bala et al., "Detection of organophosphorus pesticide - Malathion in environmental samples using peptide and aptamer based nanoprobes," Chem. Eng. J., vol. 311, pp. 111-116, 2017.

[12] S. Cui et al., "Effects of season and sediment-water exchange processes on the partitioning of pesticides in the catchment environment: Implications for pesticides monitoring," Sci. Total Environ., vol. 698, p. 134228,2020

[13] M. Arias-Estévez, E. López-Periago, E. Martínez-Carballo, J. SimalGándara, J. C. Mejuto, and L. García-Río, "The mobility and degradation of pesticides in soils and the pollution of groundwater resources," Agric. Ecosyst. Environ. vol. 123, no. 4, pp. 247-260, 2008.

[14] P. Chawla, R. Kaushik, V. J. Shiva Swaraj, and N. Kumar, "Organophosphorus pesticides residues in food and their colorimetric detection," Environ. Nanotechnology, Monit. Manag. vol. 10, pp. 292 307, 2018

[15] M. Tankiewicz, "Determination of selected priority pesticides in high water fruits and vegetables by modified QuEChERS and GC-ECD with GC-MS/MS confirmation," Molecules, vol. 24, no. 3, 2019.

[16] M. Citartan and T. H. Tang, "Recent developments of aptasensors expedient for point-of-care (POC) diagnostics," Talanta, vol. 199, no. February, pp. 556-566, 2019.

[17] C. Zhang et al., "Organophosphorus pesticides detection using broadspecific single-stranded DNA based fluorescence polarization aptamer assay," Biosens. Bioelectron. vol. 55, pp. 216-219, 2014.

[18] S. Uniyal and R. K. Sharma, "Technological advancement in electrochemical biosensor-based detection of Organophosphate pesticide chlorpyrifos in the environment: A review of status and prospects," Biosens. Bioelectron. vol. 116, no. May, pp. 37-50, 2018.

[19] N. George, P. Chauhan, S. Sondhi, S. Saini, N. Puri, and N. Gupta, "Biodegradation and analytical methods for detection of organophosphorous pesticide: chlorpyrifos," Int. J. Pure Appl. Sci. Technol., vol. 20, no. 2, p. 79, 2014

[20] D. Hu et al., "Pesticide residues in vegetables in four regions of Jilin Province," Int. J. Food Prop., vol. 23, no. 1, pp. 1150-1157, 2020.

[21] M. S. Hossain, A. N. M. Fakhruddin, M. A. Z. Chowdhury, and M. K. Alam, "Degradation of chlorpyrifos, an organophosphorus insecticide in aqueous solution with gamma irradiation and natural sunlight," J. Environ. Chem. Eng., vol. 1, no. 3, pp. 270-274, 2013

[22] Y. Yao, G. Wang, G. Chu, X. An, Y. Guo, and X. Sun, "The development of a novel biosensor based on gold nanocages/graphene oxide-chitosan modified acetylcholinesterase for organophosphorus pesticide detection," New J. Chem., vol. 43, no. 35, pp. 13816-13826, 2019.

[23] M. A. Dar, G. Kaushik, and J. F. Villarreal-Chiu, "Pollution status and bioremediation of chlorpyrifos in environmental matrices by the application of bacterial communities: A review," J. Environ. Manage. vol. 239, no. February, pp. 124-136, 2019.

[24] J. M. Giddings, M. W. Williams, K. R. Solomon, and J. P. Giesy, Reviews of environmental contamination and toxicology: risks to aquatic organisms from use of chlorpyrifos in the United States, vol. 231. 2014.

[25] O. Lockridge, L. Verdier, and L. M. Schopfer, "Half-life of chlorpyrifos oxon and other organophosphorus esters in aqueous solution," Chem. Biol. Interact., vol. 311, no. June, p. 108788, 2019.

[26] X. Wu et al., "A molecular approach to rationally constructing specific fluorogenic substrates for the detection of acetylcholinesterase activity in live cells, mice brains and tissues," Chem. Sci., vol. 11, no. 41, pp. 11285-11292, 2020

[27] M. Ali et al., "Chlorpyrifos mediated oxidative damage and histopathological alterations in freshwater fish Oncorhynchus mykiss in Northern Pakistan,” Aquac. Res., vol. 51, no. 11, pp. 4583-4594, 2020.

[28] A. L. Rathod and R. K. Garg, "Chlorpyrifos poisoning and its implications in human fatal cases: A forensic perspective with reference to Indian scenario," J. Forensic Leg. Med., vol. 47, pp. 29-34, 2017.

[29] Y. Jiao et al., "A nanostructured electrochemical aptasensor for highly sensitive detection of chlorpyrifos," Sensors Actuators, B Chem., vol. 243, pp. 1164-1170, 2017.

[30] S. O. Pehkonen and Q. Zhang, "Critical Reviews in Environmental Science and Technology the Degradation of Organophosphorus
Pesticides in Natural Waters. Environ. Sci. Technol., no. November 2013, pp. 37-41, 2010.

[31] L. K. Chai, M. H. Wong, and H. C. Bruun Hansen, "Degradation of chlorpyrifos in humid tropical soils," J. Environ. Manage. vol. 125, pp. 28-32, 2013 .

[32] Baez, M.E., Espinoza, J., Silva, R. et al. "Sorption-desorption behavior of pesticides and their degradation products in volcanic and nonvolcanic soils: interpretation of interactions through two-way principal component analysis". Environ Sci Pollut Res 22, 8576-8585 (2015). https://doi.org/10.1007/s11356-014-4036-8

[33] I. Md Meftaul, K. Venkateswarlu, R. Dharmarajan, P. Annamalai, and M. Megharaj, "Pesticides in the urban environment: A potential threat that knocks at the door," Sci. Total Environ., vol. 711, p. 134612, 2020.

[34] C. S. Caramello, C. F. Cowper, M. J. Jorge, J. E. Pérez, and L. C. Jorge, "Anormalidades morfológicas nucleares en hematíes del pez Prochilodus linneatus expuesto al clorpirifós," Rev. Vet., vol. 30, no. 2 , p. 64, 2019.

[35] C. S. Pundir, A. Malik, and Preety, "Bio-sensing of organophosphorus pesticides: A review,” Biosens. Bioelectron. vol. 140, no. May 2019.

[36] K. Pozo et al., "Occurrence of chlorpyrifos in the atmosphere of the Araucanía Region in Chile using polyurethane foam-based passive air samplers," Atmos. Pollut. Res., vol. 7, no. 4, pp. 706-710, 2016.

[37] S. Cortes et al., "First measurement of human exposure to current use pesticides (CUPs) in the atmosphere of central Chile: The case study of Mauco cohort," Atmos. Pollut. Res., vol. 11, no. 4, pp. 776-784, 2020.

[38] M. J. Climent, E. Herrero-Hernández, M. J. Sánchez-Martín, M. S Rodríguez-Cruz, P. Pedreros, and R. Urrutia, "Residues of pesticides and some metabolites in dissolved and particulate phase in surface stream water of Cachapoal River basin, central Chile," Environ. Pollut. vol. 251, pp. 90-101, 2019.

[39] M. Bhanti and A. Taneja, "Contamination of vegetables of different seasons with organophosphorous pesticides and related health risk assessment in northern India," Chemosphere, vol. 69, no. 1, pp. 63-68, 2007.

[40] T. Silipunyo et al., "Determination of Organophosphate Pesticides Residues in Fruits, Vegetables and Health Risk Assessment among Consumers in Chiang Mai Province, Northern Thailand," Res. J. Environ. Toxicol. vol. 11, no. 1, pp. 20-27, 2016.

[41] INIA, "Boletín Inia No 348," pp. 22-23, 2017.

[42] C. Cruzeiro, M. Â. Pardal, E. Rocha, and M. J. Rocha, "Occurrence and seasonal loads of pesticides in surface water and suspended particulate matter from a wetland of worldwide interest - the Ria Formosa Lagoon, Portugal,” Environ. Monit. Assess. vol. 187, no. 11, 2015.

[43] R. N. Lerch, C. H. Lin, K. W. Goyne, R. J. Kremer, and S. H. Anderson, "Vegetative Buffer Strips for Reducing Herbicide Transport in Runoff: Effects of Buffer Width, Vegetation, and Season," J. Am. Water Resour. Assoc., vol. 53, no. 3, pp. 667-683, 2017.

[44] J. Bellas and I. Gil, "Polyethylene microplastics increase the toxicity of chlorpyrifos to the marine copepod Acartia tonsa," Environ. Pollut. vol. 260 , p. 114059,2020

[45] F. Wang, J. Yao, H. Chen, K. Chen, P. Trebše, and G. Zaray, "Comparative toxicity of chlorpyrifos and its oxon derivatives to soil microbial activity by combined methods," Chemosphere, vol. 78 , no. 3 , pp. 319-326, 2010.

[46] A. Masiá, J. Campo, A. Navarro-Ortega, D. Barceló, and Y. Picó, "Pesticide monitoring in the basin of Llobregat River (Catalonia, Spain) and comparison with historical data," Sci. Total Environ., vol. 503-504, pp. 58-68, 2015.

[47] H. B. Mathur, H. C. Agarwal, S. Johnson, and N. Saikia, "Analysis of Pesticide Residues in Blood Samples from Villages of Punjab INVESTIGATORS CSE Report: Analysis of Pesticide Residues in blood samples from villages of Punjab," no. January 2005, 2005.

[48] M. Bigot et al., "Air-Seawater Exchange of Organochlorine Pesticides in the Southern Ocean between Australia and Antarctica," Environ. Sci. Technol., vol. 50, no. 15, pp. 8001-8009, 2016.

[49] K. W. Hwang, S. C. Yoo, S. E. Lee, and J. K. Moon, "Residual level of chlorpyrifos in lettuces grown on chlorpyrifos-treated soils," Appl. Sci., vol. 8, no. $12,2018$.

[50] L. Wang, Z. Liu, J. Zhang, Y. Wu, and H. Sun, "Chlorpyrifos exposure in farmers and urban adults: Metabolic characteristic, exposure estimation, and potential effect of oxidative damage," Environ. Res., vol. 149, pp. 164-170, 2016.

[51] R. Sanghi, M. K. K. Pillai, T. R. Jayalekshmi, and A. Nair, "Organochlorine and organophosphorus pesticide residues in breast 
milk from Bhopal, Madhya Pradesh, India," Hum. Exp. Toxicol., vol. 22, no. 2, pp. 73-76, 2003.

[52] Y. Han et al., "Pesticide residues in nut-planted soils of China and their relationship between nut/soil," Chemosphere, vol. 180, pp. 42-47, 2017.

[53] D. Marchis, G. L. Ferro, P. Brizio, S. Squadrone, and M. C. Abete, "Detection of pesticides in crops: A modified QuEChERS approach," Food Control, vol. 25, no. 1, pp. 270-273, 2012.

[54] V. H. Estellano, K. Pozo, C. Efstathiou, K. Pozo, S. Corsolini, and S. Focardi, "Assessing levels and seasonal variations of current-use pesticides (CUPs) in the Tuscan atmosphere, Italy, using polyurethane foam disks (PUF) passive air samplers," Environ. Pollut. vol. 205, pp. $52-59,2015$.

[55] F. Arduini, F. Ricci, C. S. Tuta, D. Moscone, A. Amine, and G. Palleschi, "Detection of carbamic and organophosphorous pesticides in water samples using a cholinesterase biosensor based on Prussian, Bluemodified screen-printed electrode," Anal. Chim. Acta, vol. 580, no. 2, pp. 155-162, 2006.

[56] G. Koukouvinos et al., "Fast simultaneous detection of three pesticides by a White Light Reflectance Spectroscopy sensing platform," Sensors Actuators, B Chem., vol. 238, pp. 1214-1223, 2017.

[57] P. B. Kurt-Karakus, C. Teixeira, J. Small, D. Muir, and T. F. Bidleman, "Current-use pesticides in inland lake waters, precipitation, and air from Ontario, Canada," Environ. Toxicol. Chem., vol. 30, no. 7, pp. 1539$1548,2011$.

[58] I. Cavoski, P. Caboni, G. Sarais, and T. Miano, "Degradation and persistence of rotenone in soils and influence of temperature variations," J. Agric. Food Chem., vol. 56, no. 17, pp. 8066-8073, 2008.

[59] A. C. Belfroid, M. Van Drunen, M. A. Beek, S. M. Schrap, C. A. M. Van Gestel, and B. Van Hattum, "Relative risks of transformation products of pesticides for aquatic ecosystems," Sci. Total Environ., vol. 222, no. 3, pp. 167-183, 1998.

[60] Simo O. Pehkonen \& Qi Zhang. "The Degradation of Organophosphorus Pesticides in Natural Waters: A Critical Review", in Environmental Science and Technology, 32:1, 17-72, 2002. DOI: $10.1080 / 10643380290813444$.

[61] R. Mosquera B. and G. A. Peñuela M., "Biodegradación del malatión utilizando microorganismos nativos de suelos agrícolas", Rev. Colomb. Cienc. Pecu. vol. 22, no. 2, pp. 189-198, Jul. 2009.

[62] M. Zhang et al., "Non-target effects of repeated chlorothalonil application on soil nitrogen cycling: The key functional gene study," Sci. Total Environ., vol. 543, pp. 636-643, 2016.

[63] V. Andreu and Y. Picó, "Determination of pesticides and their degradation products in soil: Critical review and comparison of methods," TrAC - Trends Anal. Chem., vol. 23, no. 10-11, pp. 772789, 2004.

[64] E. Borrás, M. Ródenas, M. Vázquez, T. Vera, and A. Muñoz, "Particulate and gas-phase products from the atmospheric degradation of chlorpyrifos and chlorpyrifos-oxon," Atmos. Environ., vol. 123, pp. $112-120,2015$.

[65] A. Muñoz, M. Ródenas, E. Borrás, M. Vázquez, and T. Vera, “The gasphase degradation of chlorpyrifos and chlorpyrifos-oxon towards $\mathrm{OH}$ radical under atmospheric conditions," Chemosphere, vol. 111, pp. 522-528, 2014

[66] C. Coscollà, A. Muñoz, E. Borrás, T. Vera, M. Ródenas, and V. Yusà, "Particle size distributions of currently used pesticides in ambient air of an agricultural Mediterranean area," Atmos. Environ., vol. 95, pp. 29 35, 2014.

[67] K. E. Murray, S. M. Thomas, and A. A. Bodour, "Prioritizing research for trace pollutants and emerging contaminants in the freshwater environment," Environ. Pollut. vol. 158, no. 12, pp. 3462-3471, 2010.

[68] M. Liu et al., "Aptasensors for pesticide detection," Biosens. Bioelectron. vol. 130, no. November 2018, pp. 174-184, 2019.

[69] F. Di Nardo and L. Anfossi, Commercial biosensors for detection of food additives, contaminants, and pathogens. Elsevier Inc., 2020.

[70] X. Wang, X. Lu, and J. Chen, "Development of biosensor technologies for analysis of environmental contaminants," Trends Environ. Anal. Chem., vol. 2, pp. 25-32, 2014.

[71] J. S. Duhan, R. Kumar, N. Kumar, P. Kaur, K. Nehra, and S. Duhan, "Nanotechnology: The new perspective in precision agriculture," Biotechnol. Reports, vol. 15, pp. 11-23, 2017.

[72] B. Bucur, F. D. Munteanu, J. L. Marty, and A. Vasilescu, "Advances in enzyme-based biosensors for pesticide detection," Biosensors, vol. 8 , no. 2, pp. 1-28, 2018.
[73] C. I. L. Justino, A. C. Duarte, and T. A. P. Rocha-Santos, "Recent progress in biosensors for environmental monitoring: A review," Sensors (Switzerland), vol. 17, no. 12, 2017.

[74] F. Li, Z. Yu, X. Han, and R. Y. Lai, "Electrochemical aptamer-based sensors for food and water analysis: A review," Anal. Chim. Acta, vol. 1051, pp. 1-23, 2019.

[75] S. Feng, Y. Hu, L. Ma, and X. Lu, "Development of molecularly imprinted polymers-surface-enhanced Raman spectroscopy/colorimetric dual sensor for determination of chlorpyrifos in apple juice," Sensors Actuators, B Chem., vol. 241, pp. 750-757, 2017.

[76] B. Kuswandi, C. I. Fikriyah, and A. A. Gani, "An optical fiber biosensor for chlorpyrifos using a single sol-gel film containing acetylcholinesterase and bromothymol blue," Talanta, vol. 74, no. 4, pp. 613-618, 2008.

[77] Q. Luo, F. Yu, F. Yang, C. Yang, P. Qiu, and X. Wang, “A 3D-printed self-propelled, highly sensitive mini-motor for underwater pesticide detection," Talanta, vol. 183, pp. 297-303, 2018

[78] O. Ademuyiwa et al., "Erythrocyte acetylcholinesterase activity as a surrogate indicator of lead-induced neurotoxicity in occupational lead exposure in Abeokuta, Nigeria," Environ. Toxicol. Pharmacol. vol. 24, no. 2, pp. 183-188, 2007.

[79] L. Rassaei, F. Marken, M. Sillanpää, M. Amiri, C. M. Cirtiu, and M. Sillanpää, "Nanoparticles in electrochemical sensors for environmental monitoring," TrAC - Trends Anal. Chem., vol. 30, no. 11, pp. 1704$1715,2011$.

[80] J. Wyrzykowska et al., "THE VISIBLE PLANT CELL: BIOSENSORS AND BIORECEPTORS."

[81] P. Röthlisberger and M. Hollenstein, "Aptamer chemistry," Adv. Drug Deliv. Rev., vol. 134, pp. 3-21, 2018.

[82] A. Verdian, "Apta-nanosensors for detection and quantitative determination of acetamiprid - A pesticide residue in food and environment," Talanta, vol. 176, pp. 456-464, 2018.

[83] M. Guler, V. Turkoglu, and Z. Basi, "Determination of malation, methidathion, and chlorpyrifos ethyl pesticides using acetylcholinesterase biosensor based on Nafion/Ag@rGO-NH2 nanocomposites," Electrochim. Acta, vol. 240, pp. 129-135, 2017.

[84] W. Wei, X. Zong, X. Wang, L. Yin, Y. Pu, and S. Liu, “A disposable amperometric immunosensor for chlorpyrifos-methyl based on immunogen/platinum doped silica sol-gel film modified screen-printed carbon electrode," Food Chem., vol. 135, no. 3, pp. 888-892, 2012.

[85] D. C. Rodríguez, S. Carvajal, and G. Peñuela, "Effect of chlorpyrifos on the inhibition of the enzyme acetylcholinesterase by cross-linking in water-supply samples and milk from dairy cattle," Talanta, vol. 111, pp. $1-7,2013$.

[86] J. Halámek, J. Přibyl, A. Makower, P. Skládal, and F. W. Scheller, "Sensitive detection of organophosphates in river water by means of a piezoelectric biosensor," Anal. Bioanal. Chem., vol. 382, no. 8, pp. 1904-1911, 2005.

[87] J. Cao et al., "Rapid colorimetric determination of the pesticides carbofuran and dichlorvos by exploiting their inhibitory effect on the aggregation of peroxidase-mimicking platinum nanoparticles," Microchim. Acta, vol. 186, no. 6, 2019.

[88] G. Xu et al., "A regenerative and selective electrochemical aptasensor based on copper oxide nanoflowers-single walled carbon nanotubes nanocomposite for chlorpyrifos detection," Talanta, vol. 178, no. May 2017, pp. 1046-1052, 2018.

[89] M. Roushani, A. Nezhadali, and Z. Jalilian, "An electrochemical chlorpyrifos aptasensor based on the use of a glassy carbon electrode modified with an electropolymerized aptamer-imprinted polymer and gold nanorods," Microchim. Acta, vol. 185, no. 12, 2018.

[90] D. Capoferri, F. Della Pelle, M. Del Carlo, and D. Compagnone, "Affinity sensing strategies for the detection of pesticides in food," Foods, vol. 7, no. 9, 2018.

[91] J. Liu, Z. Guan, Z. Lv, X. Jiang, S. Yang, and A. Chen, "Improving sensitivity of gold nanoparticle-based fluorescence quenching and colorimetric aptasensor by using water resuspended gold nanoparticle," Biosens. Bioelectron. vol. 52, pp. 265-270, 2014.

[92] S. Nagabooshanam, S. Roy, A. Mathur, I. Mukherjee, S. Krishnamurthy, and L. M. Bharadwaj, "Electrochemical micro analytical device interfaced with portable potentiostat for rapid detection of chlorpyrifos using acetylcholinesterase conjugated metal organic framework using Internet of things," Sci. Rep., vol. 9, no. 1, pp. $1-9,2019$.

[93] N. K. Mogha, V. Sahu, M. Sharma, R. K. Sharma, and D. T. Masram, "Biocompatible $\mathrm{ZrO} 2$ - reduced graphene oxide immobilized $\mathrm{AChE}$ 
biosensor for chlorpyrifos detection," Mater. Des. vol. 111, pp. 312 320, 2016.

[94] Y. Mao et al., "A simple and sensitive aptasensor for colorimetric detection of adenosine triphosphate based on unmodified gold nanoparticles," Talanta, vol. 168, pp. 279-285, 2017.

[95] N. Kaur and N. Prabhakar, "Current scenario in organophosphates detection using electrochemical biosensors," TrAC - Trends Anal. Chem., vol. 92, pp. 62-85, 2017.

[96] F. Wang, J. Yao, H. Chen, K. Chen, P. Trebše, and G. Zaray, "Comparative toxicity of chlorpyrifos and its oxon derivatives to soil microbial activity by combined methods," Chemosphere, vol. 78 , no. 3 , pp. 319-326, 2010.

[97] F. Arduini, S. Cinti, V. Scognamiglio, and D. Moscone, "Nanomaterials in electrochemical biosensors for pesticide detection: advances and challenges in food analysis," Microchim. Acta, vol. 183, no. 7, pp. 2063-2083, 2016

[98] S. Andreescu, L. Barthelmebs, and J. L. Marty, "Immobilization of acetylcholinesterase on screen-printed electrodes: Comparative study between three immobilization methods and applications to the detection of organophosphorus insecticides," Anal. Chim. Acta, vol. 464, no. 2, pp. 171-180, 2002.

[99] I. Ion, A. Culetu, and D. Gherase, "Environmental Applications of Carbon-Based Nanomaterials. Acetylcholinesterase Biosensors for Organophosphate Pesticide Analysis," Environ. Appl. Carbon-Based Nanomater. Acetylcholinesterase Biosens. Organophosphate Pestic. Anal., pp. 34-50, 2006.

[100] M. Gao, "Detection by Using Fe 3 O 4 Nanoparticle Aggregates as Color Reagents," Anal. Chem., pp. 6778-6784, 2011.

[101] K. Sankar et al., "Digital image-based quantification of chlorpyrifos in water samples using a lipase embedded paper-based device," Talanta, vol. 208, no. September 2019, p. 120408, 2020.

[102] X. Sun, L. Qiao, X. Sun, and X. Wang, "Pesticide residues rapid detection in vegetables real samples based on nanomaterial-modified acetylcholinesterase biosensor," Micro Nano Lett., vol. 8, no. 7, pp. 330-335, 2013

[103] Y. P. Chen et al., "A rapid and sensitive fluoroimmunoassay based on quantum dot for the detection of chlorpyrifos residue in drinking water," J. Environ. Sci. Heal. - Part B Pestic. Food Contam. Agric. Wastes, vol. 45 , no. 6 , pp. $508-515,2010$.

[104] S. Islam et al., "Microfluidic-based graphene field effect transistor for femtomolar detection of chlorpyrifos," Sci. Rep., vol. 9, no. 1, pp. 1-7, 2019.

[105] N. Prabhakar et al., "Polypyrrole-polyvinyl sulphonate film based disposable nucleic acid biosensor, Analytica Chimica Acta, Vol. 589, 2007.

[106] R. Pratima et al., "Nucleic acid sensor for insecticide detection," J. Mol. Recognit. 2008; 21: 217-223.

[107] K. Zhang et al., "Ligand Replacement-Induced Fluorescence Switch of Quantum Dots for Ultrasensitive Detection of Organophosphorothioate Pesticides," Anal. Chem., (82), 9579-9586, 2010.

[108] C. Xien et al., "Surface Molecular Self-Assembly for Organophosphate Pesticide Imprinting in Electropolymerized Poly(p-aminothiophenol) Membranes on a Gold Nanoparticle Modified Glassy Carbon Electrode. "Anal. Chem., (82), 241-249, 2010.

[109] P. Weerathunge et al., "Dynamic interactions between peroxidasemimic silver NanoZymes and chlorpyrifos-specific aptamers enable highly-specific pesticide sensing in river water," Anal. Chim. Acta, vol. 1083, pp. 157-165, 2019.

[110] N. Cheng, etal., "Aptasensor based on fluorophore-quencher nano-pair and smartphone spectrum reader for on-site quantification of multipesticides,Biosensors and Bioelectronics,Volume 117, pp. 75-83 2018.

[111] W. Whangsuk et al., "Specific detection of the pesticide chlorpyrifos by a sensitive genetic-based whole cell biosensor, Analytical Biochemistry, Volume 493, pp.11-13, 2016.

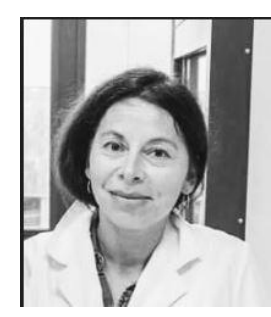

Mariett Alejandra Torres Gutierrez. Químico Marino (2015) y Diplomado en Sistemas de Información Geográfica (2018) de la Universidad católica de la santísima Concepción, Chile. Magister (C) en Innovación en Biociencias y Bioingeniería de la Universidad San Sebastián, Chile. Experiencia laboral en monitoreo de compuestos orgánicos persistente (COPs) y contaminación por microplásticos en matrices ambientales, organización profesional Facultad de Ingeniería y Tecnología de la Universidad San Sebastián, Chile. Las áreas de interés monitoreo, detección e identificación de compuestos tóxicos con efectos en salud pública y medio ambiente.

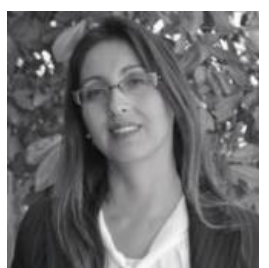

Karla Andrea Pozo Gallardo. Biólogo Marino, Universidad Católica de la Santísima Concepción. Chile (1998). PhD Ciencias Ambientales, Universidad di Siena, Italia (2004). Experiencia en el estudio de la distribución de Contaminantes orgánicos persistentes (COPs), destino ambiental de COPs, Química de la Atmósfera, Contaminación ambiental, Marcadores tempranos de contaminación en ambientes acuáticos, Oceanografía Química y toxicología Ambiental. Directora de dos proyectos Fondecyt Regulares Chile y Coordinadora Grupo de Contaminación Ambiental por Microplásticos y Contaminantes Orgánicos Persistentes de la facultad de Ingeniería y tecnología de la universidad San Sebastián, Chile Afiliación al Centro de Investigación de Compuestos Tóxicos en el Medio Ambiente (RECETOX) República Checa y Universidad San Sebastián, Chile. Área de investigaciones contaminantes ambientales y emergentes en matrices abióticas y bióticas.

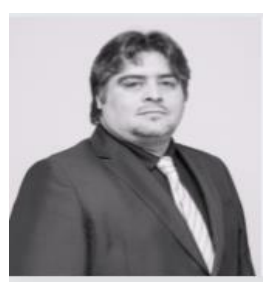

Víctor Manuel Díaz García. Bioquímico, Universidad de Santiago de Chile. PhD. en Bioquímica -especialidad Nanotecnología Universidad de Chile. Experiencia en el área de investigación orientado al uso de nanopartículas, para el desarrollo de biosensores optoelectrónicos basados en procesamiento de señales ópticas emitidas por nanopartículas de oro (plasmónica) y puntos cuánticos (fotónica), para detección de contaminantes alimentarios y ambientales. Coordinador Núcleo de Nanotecnología y Materiales Avanzados de la Facultad de ingeniería y tecnología de la Universidad San Sebastián, Chile. Área de Investigación Aplicación de nano materiales en biomedicina y nano sensores. 